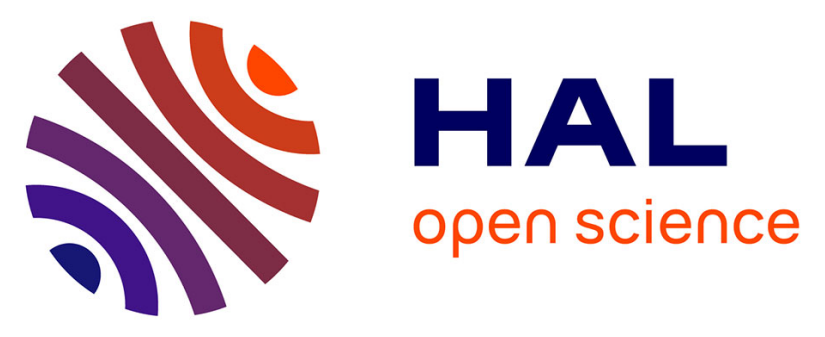

\title{
Achieving Ultrahigh Piezoelectricity in Organic-Inorganic Vacancy-Ordered Halide Double Perovskites for Mechanical Energy Harvesting
}

Guangguang Huang, Asif Abdullah Khan, Md Masud Rana, Chao Xu, Shuhong Xu, Resul Saritas, Steven Zhang, Eihab Abdel-Rahmand, Pascal Turban, Soraya Ababou-Girard, et al.

\section{To cite this version:}

Guangguang Huang, Asif Abdullah Khan, Md Masud Rana, Chao Xu, Shuhong Xu, et al.. Achieving Ultrahigh Piezoelectricity in Organic-Inorganic Vacancy-Ordered Halide Double Perovskites for Mechanical Energy Harvesting. ACS Energy Letters, 2021, 6 (1), pp.16-23. 10.1021/acsenergylett.0c02200 . hal-03124235

HAL Id: hal-03124235

https://hal-univ-rennes1.archives-ouvertes.fr/hal-03124235

Submitted on 22 Feb 2021

HAL is a multi-disciplinary open access archive for the deposit and dissemination of scientific research documents, whether they are published or not. The documents may come from teaching and research institutions in France or abroad, or from public or private research centers.
L'archive ouverte pluridisciplinaire HAL, est destinée au dépôt et à la diffusion de documents scientifiques de niveau recherche, publiés ou non, émanant des établissements d'enseignement et de recherche français ou étrangers, des laboratoires publics ou privés. 


\section{Achieving Ultrahigh Piezoelectricity in Organic-}

2 Inorganic Vacancy-Ordered Halide Double

\section{Perovskites for Mechanical Energy Harvesting}

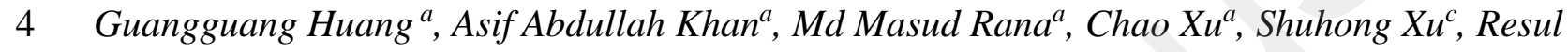

5 Saritas $^{d}$, Steven Zhang ${ }^{a}$, Eihab-Abdel Rahman ${ }^{d}$, Pascal Turban ${ }^{f}$, Soraya Ababou-Girard ${ }^{f}$, Chunlei

6 Wang $^{*}$, Dayan Ban ${ }^{* a, b, e}$

$7 \quad{ }^{a}$ Waterloo Institute for Nanotechnology, University of Waterloo, 200 University Ave West,

8 Waterloo, ON, Canada

$9 \quad{ }^{\mathrm{b}}$ Department of Electrical and Computer Engineering, University of Waterloo, 200 University

10 Ave, Waterloo, ON, Canada

11 c Advanced Photonics Center, School of Electronic Science and Engineering, Southeast

12 University, Nanjing, 210096, P. R. China

13 d Department of Systems Design Engineering, University of Waterloo, 200 University Ave,

14 Waterloo, N2L 3G1 ON, Canada

$15{ }^{\mathrm{e}}$ School of Physics and Electronics, Henan University, No. 1 Jinming street, Kaifeng, Henan, P.

16 R. China

$17{ }^{\mathrm{f}}$ Univ Rennes, CNRS, IPR (Institut de Physique de Rennes) - UMR 6251, F-35000 AUTHOR

\section{Corresponding Author}

19 E-mail: wangchl@seu.edu.cn and dban@uwaterloo.ca 


\section{ABSTRACT}

2 Piezoelectric charge coefficient $\left(\mathrm{d}_{33}\right)$ and piezoelectric voltage coefficient $\left(\mathrm{g}_{33}\right)$ are the two most

3 critical parameters that define output performance of piezoelectric nanogenerators (PNGs). Herein,

4 we propose a vacancy-ordered double perovskite of $\mathrm{TMCM}_{2} \mathrm{SnCl}_{6}$ (where $\mathrm{TMCM}$ is

5 trimethylchloromethyl ammonium) with a large $\mathrm{d}_{33}$ of $137 \mathrm{pC} / \mathrm{N}$ and $\mathrm{g}_{33}$ of $980 \times 10^{-3} \mathrm{~V} \cdot \mathrm{m} / \mathrm{N}$. The

6 piezoelectric coefficients are considered from the halogen-bonding mediated synergistic

7 movements of atomic displacement in inorganic $\left[\mathrm{SnCl}_{6}\right]^{2-}$ octahedrons, as well as the molecular

8 rotation of organic $\mathrm{TMCM}^{+}$, which is revealed by a combined density functional theory (DFT) and

9 experimental study. The $\mathrm{TMCM}_{2} \mathrm{SnCl}_{6}$ possesses a high saturated polarization $\left(\mathrm{P}_{\mathrm{s}}\right)$ of $8.7 \mu \mathrm{C} / \mathrm{cm}^{2}$,

10 a high Curie temperature $\left(\mathrm{T}_{\mathrm{c}}\right)$ of $365 \mathrm{~K}$, and a low coercive field $\left(\mathrm{E}_{\mathrm{c}}\right)$ of $0.6 \mathrm{kV} / \mathrm{cm}$. The output

11 voltage $\left(\mathrm{V}_{\mathrm{oc}}\right)$ and current $\left(\mathrm{I}_{\mathrm{sc}}\right)$ of the PNGs are $81 \mathrm{~V}$ and $2 \mu \mathrm{A}$ at an applied mechanical excitation

12 of $(4.9 \mathrm{~N}, 40 \mathrm{~Hz})$. We hope this work will provide guidance in energy harvesting by innovatively

13 designing highly piezoelectric perovskites for the PNGs.

\section{TOC GRAPHICS}

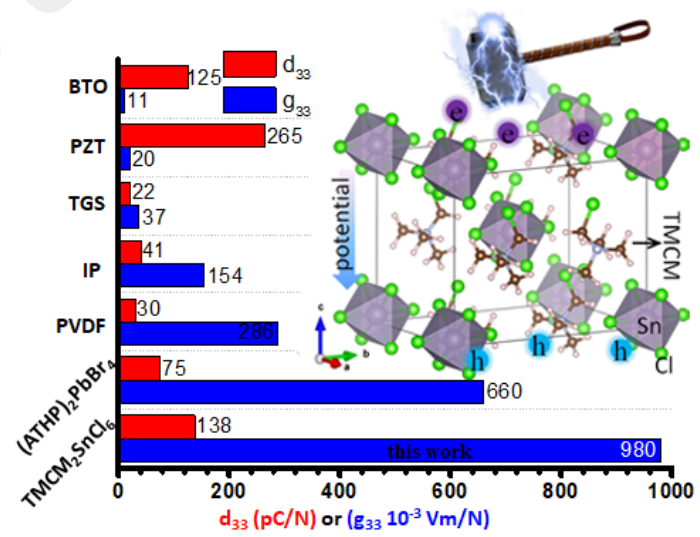


Piezoelectric nanogenerators (PNGs) have been emerging as a promising power source for self-

2 powered electronics owing to their direct power conversion from mechanical to electrical energy. ${ }^{1-}$

$3{ }^{5}$ To maximize the output power of PNGs, both the $d_{33}$ and $g_{33}$ of the piezoelectric host are

4 important, which determines the output current $\left(\mathrm{I}_{\mathrm{sc}}=\left(\mathrm{d}_{33} \times \Delta \mathrm{F}\right) / \Delta \mathrm{t}\right.$, where $\Delta \mathrm{F}$ is the applied force

5 and $\Delta \mathrm{t}$ is the time) and voltage $\left(\mathrm{V}_{\mathrm{oc}}=\mathrm{g}_{33} \times \Delta \mathrm{P} \times \mathrm{L}\right.$, where $\Delta \mathrm{P}$ is the applied pressure and $\mathrm{L}$ is the

6 original film thickness), respectively.$^{6-9}$ In the past decade, a wide range of piezoelectric materials,

7 targeting high $g_{33}$ or $d_{33}$, have been synthesized for the efficient PNGs. For example, the organic

8 polyvinylidene fluoride (PVDF) possesses a high $\mathrm{g}_{33}\left(\sim 286 \times 10^{-3} \mathrm{~V} \cdot \mathrm{m} / \mathrm{N}\right)$, leading to a high output

9 piezoelectric voltage. Unfortunately, the resultant current is limited due to its relatively-low $\mathrm{d}_{33}$

$10(\sim 30 \mathrm{pC} / \mathrm{N}) \cdot{ }^{10-13}$ Conversely, inorganic perovskite oxide ceramics, including $\mathrm{PbZr}_{\mathrm{x}} \mathrm{Ti}_{1-\mathrm{x}} \mathrm{O}_{3}(\mathrm{PZT})$

11 and $\mathrm{BaTiO}_{3}(\mathrm{BTO})$, exhibit a high $\mathrm{d}_{33}(>100 \mathrm{pC} / \mathrm{N})$ but their $\mathrm{g}_{33}$ is rather low $\left(\sim 20 \times 10^{-3} \mathrm{~V} \cdot \mathrm{m} / \mathrm{N}\right) .{ }^{14-}$

$12{ }^{18}$ Considering the relation between $d_{33}$ and $g_{33}\left(g_{33}=d_{33} /\left(\varepsilon_{0} \times \varepsilon_{r}\right)\right)$, where $\varepsilon_{\mathrm{r}}$ is material relative

13 permittivity, it is challenging to improve $d_{33}$ while maintaining a high $g_{33}$ because the increase of

$14 \mathrm{~d}_{33}$ is usually associated with an even larger increase of $\varepsilon_{\mathrm{r} \cdot}{ }^{19}$

15 Organic-inorganic hybrid perovskites (OIHPs) combine the merits of both organic molecules

16 and crystalline inorganic solids at a molecular level. The OIHPs were firstly introduced to solar

17 cells (SCs) due to their excellent optical properties in 2009 and then adopted in piezoelectric

18 reseach. ${ }^{20-25}$ In 2015, the $\mathrm{MAPbI}_{3}$ was firstly employed in PNGs which yielded an output voltage

19 and current density of $2.7 \mathrm{~V}$ and $140 \mathrm{nA} / \mathrm{cm}^{2}$ at a pressure of $0.5 \mathrm{MPa} .{ }^{26}$ Subsequently, a series of

20 perovskites, including $\mathrm{MASnBr}_{3}, \mathrm{FAPbBr}_{2} \mathrm{I}$ and $\mathrm{Cl} / \mathrm{Br}-\mathrm{MAPbI}_{3}$, have been developed for efficient

21 PNGs via the piezoelectric composite films. ${ }^{27-31}$ However, the aforementioned OIHPs evolved

22 from the shadows of the SCs possess limited piezoelectric coefficients. Therefore, extensive efforts

23 have been devoted to searching for highly piezoelectric OIHPs. Remarkably, one-dimensional 
$1 \mathrm{ABX}_{3}$-type OIHPs with high $\mathrm{d}_{33}$, including the $\mathrm{TMCM}^{-\mathrm{MnCl}_{3}}$ and A-site mixed

2 (TMFM) $)_{x}(\mathrm{TMCM})_{1-\mathrm{x}} \mathrm{CdCl}_{3}$, were synthesized in 2017 and 2019, respectively. ${ }^{32,} 33$ Two-

3 dimensional (ATHP) $)_{2} \mathrm{PbBr}_{4}$ OIHPs with large $\mathrm{d}_{33}$ of $75 \mathrm{pC} / \mathrm{N}$ and giant $\mathrm{g}_{33}$ of $660 \times 10^{-3} \mathrm{~V} \cdot \mathrm{m} / \mathrm{N}$

4 were reported in $2019 .{ }^{34}$ In 2020, the OIHPs were further developed and successfully employed in

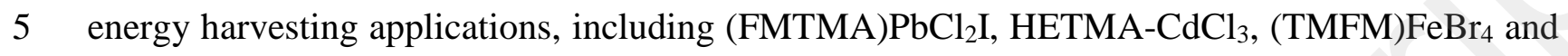

$6 \quad\left[\mathrm{Ph}_{3} \mathrm{MeP}\right]_{4}\left[\mathrm{Ni}(\mathrm{NCS})_{6}\right] \cdot{ }^{35-38}$ Despite their large piezoelectric coefficients, the newly-developed

7 OIHPs may suffer substantial difficulties in mass production and implementation. For example,

8 the $\mathrm{TMCM}-\mathrm{MnCl}_{3}$ has intrinsic chemical instability as the bivalent $\mathrm{Mn}$ is prone to be oxidized to

9 tetravalent, while the $\mathrm{Cd}($ or $\mathrm{Pb})$ in $(\mathrm{TMFM})_{\mathrm{x}}(\mathrm{TMCM})_{1-\mathrm{x}} \mathrm{CdCl}_{3}$ (or $(\mathrm{ATHP})_{2} \mathrm{PbBr}_{4}$ ) is not

10 environmental-friendly. Unlike the $\mathrm{ABX}_{3}$-type OIHPs, the $\mathrm{A}_{2} \mathrm{BX}_{6}$ OIHPs (such as $\mathrm{K}_{2} \mathrm{PtCl}_{6}$ ) are

11 potentially more chemically stable because their B-site is already in the tetravalent state. ${ }^{39-41}$

12 Herein, we proposed an alternative crystal model, which was vacancy-ordered double OIHPs,

13 for novel piezoelectric material design. The chemical formula was confirmed as $\mathrm{TMCM}_{2} \mathrm{SnCl}_{6}$ via

14 powder X-ray diffraction (XRD) and X-ray photoelectron spectroscopy (XPS). The large $\mathrm{d}_{33}$ of

$15137 \mathrm{pC} / \mathrm{N}$ and giant $\mathrm{g}_{33}$ of $980 \times 10^{-3} \mathrm{~V} \cdot \mathrm{m} / \mathrm{N}$ were experimentally measured for the prepared

$16 \mathrm{TMCM}_{2} \mathrm{SnCl}_{6}$ crystal, which was further confirmed by the DFT study and the outputs of PNGs.

17 The PNGs were fabricated via sandwiching the $\mathrm{TMCM}_{2} \mathrm{SnCl}_{6} @ \mathrm{PDMS}$ composite film into two

18 copper electrodes, where PDMS represents Poly(dimethylsiloxane). A self-powered wireless

19 communication node (SWCN) was successfully driven by the PNG. The detailed material

20 synthesis and device fabrication processes are shown in the supporting information. 


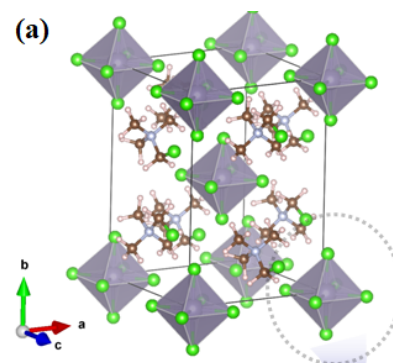

(d)

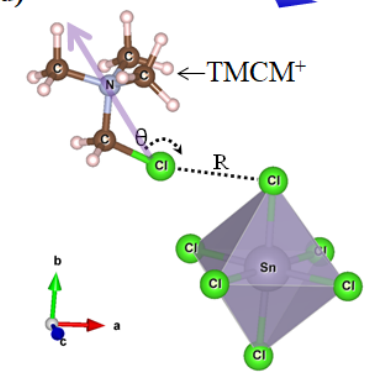

(b)

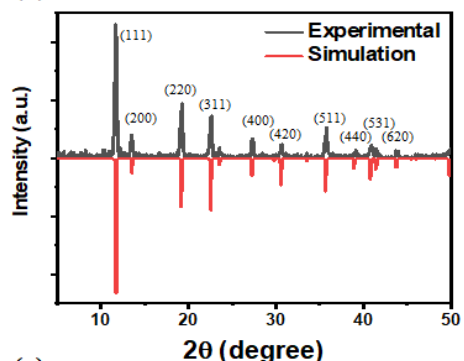

(e)

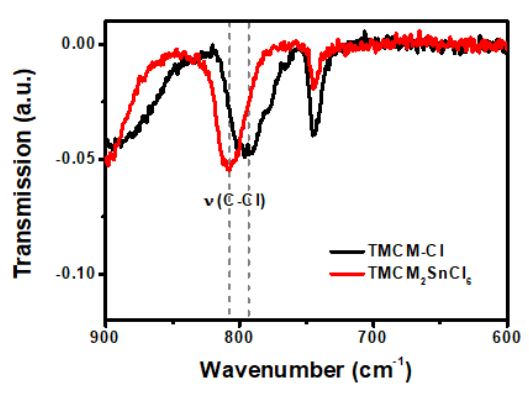

(c)

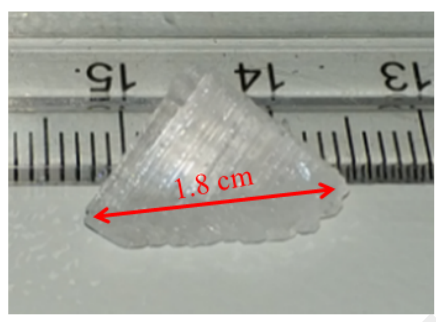

(f)

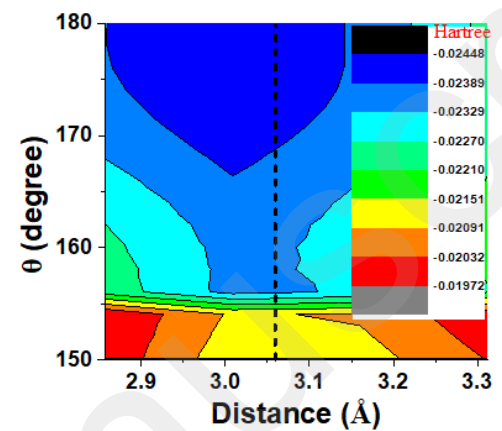

Figure 1. Crystal structure of $\mathrm{TMCM}_{2} \mathrm{SnCl}_{6}$ double perovskites: (a) structural model; (b)

3 calculated and experimental XRD patterns; (c) digital photograph of single crystal; (d) halogen

4 bonding interaction. The arrow from $\mathrm{Cl}$ to $\mathrm{N}$ indicates the dipole direction of $\mathrm{TMCM}^{+}$; (e) FTIR

5 spectra of pure TMCM-Cl molecules and $\mathrm{TMCM}_{2} \mathrm{SnCl}_{6}$; (f) calculated energy mapping of halogen

6 bond for the simplified model in Figure 1d.

$8 \mathrm{TMCM}_{2} \mathrm{SnCl}_{6}$ is a vacancy-ordered double perovskite because its $50 \%\left[\mathrm{SnCl}_{6}\right]^{2-}$ octahedrons

9 are replaced by periodic vacancies, in which the asymmetric $\mathrm{TMCM}^{+}$takes the $\mathrm{A}$ sites (Figure

10 1a). This is different from the reported vacancy-ordered double perovskites with spherical

11 symmetric cations like trimethylmethyl ammonium (TMA) or monovalent alkali metals (Na, K,

12 Cs...) taking the A sites. ${ }^{42-44}$ Figure $1 \mathbf{b}$ shows the XRD measured from the $\mathrm{TMCM}_{2} \mathrm{SnCl}_{6}$ single

13 crystals (black curve) in comparison to the simulated XRD (red curve) from the projected structure

14 in Figure 1a. The single crystal of $\mathrm{TMCM}_{2} \mathrm{SnCl}_{6}$ with a length of $1.8 \mathrm{~cm}$ is shown in Figure 1c. 
1 The agreement of XRD peaks confirms the crystal structure and its high phase purity. The

$2 \mathrm{TMCM}_{2} \mathrm{SnCl}_{6}$ was aged to 6 months in an ambient atmosphere and the XRD was measured in

3 Figure S1a. The reflection peaks of $\mathrm{TMCM}_{2} \mathrm{SnCl}_{6}$ almost remained unchanged and no new

4 reflection peaks appeared. These indicate the $\mathrm{TMCM}_{2} \mathrm{SnCl}_{6}$ crystals have not degraded into other

5 chemicals and exhibit good stability. The $\mathrm{TMCM}_{2} \mathrm{SnCl}_{6}$ also exhibits good thermal stability, as

6 indicated by a negligible change in the measured permittivity at 340K for one hour (Figure S1d).

7 The chemical states of (TMCM) ${ }_{2} \mathrm{SnCl}_{6}$ were measured via XPS in Figure S2. The peaks at binding

8 energy of $495.8 \mathrm{eV}$ and $487.3 \mathrm{eV}$ are assigned to $\mathrm{Sn}^{4+}$ and corresponding to its $3 \mathrm{~d}_{3 / 2}$ and $3 \mathrm{~d}_{5 / 2}$

9 orbitals, respectively. The peaks at $200.6 \mathrm{eV}$ and $198.8 \mathrm{eV}$ are assigned to $3 \mathrm{p}_{1 / 2}$ and $3 \mathrm{p}_{3 / 2}$ orbitals

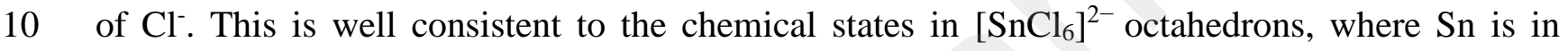

11 tetravalent state and $\mathrm{Cl}$ in minus state.

12 A halogen bond has been considered as an efficient driving force to achieve the well-defined

13 structures during crystal growth for piezoelectric properties. ${ }^{45,}{ }^{46} \mathrm{In} \mathrm{TMCM}_{2} \mathrm{SnCl}_{6}$, there is a net

14 attractive interaction between an electrophilic region associated with the $\mathrm{Cl}$ atom in $\mathrm{TMCM}^{+}$and

15 the nucleophilic $\mathrm{Cl}^{-}$in the $\left[\mathrm{SnCl}_{6}\right]^{2-}$ octahedron (Figure 1d). The attractive nature of the halogen

16 bond is determined by the bond distance (R, in the range of 2-6 $\AA$ ) and the bond angle $(\theta$, in the

17 range of $150-180^{\circ}$ ), especially when $\mathrm{R}$ is shorter than the sum of Van der Waals radii ( $3.5 \AA$ ).

18 The halogen bond in the $\mathrm{TMCM}_{2} \mathrm{SnCl}_{6}$ was reflected by Fourier transform infrared spectroscopy

19 (FTIR) in Figure 1e. The absorption peak at $793 \mathrm{~cm}^{-1}$ (black line) is attributed to the stretching

20 vibration of $\mathrm{Cl}-\mathrm{C}$ bond of $\mathrm{TMCM}^{+}$. For the $\mathrm{TMCM}_{2} \mathrm{SnCl}_{6}$, the absorption peak has a red-shift of

$2114 \mathrm{~cm}^{-1}$ to $807 \mathrm{~cm}^{-1}$ (red line). The red shift should be attributed to the increased force constant

22 when the electrophilic $\mathrm{Cl}$ in $\mathrm{TMCM}^{+}$is attracted by the nucleophilic $\mathrm{Cl}$ in $\left[\mathrm{SnCl}_{6}\right]^{2-}$ octahedron

23 according to harmonic motion for diatomic model. ${ }^{47,}{ }^{48}$ The halogen bond energy was calculated 
1 by using DFT as a function of the bond distance (R) and the bond angle $(\theta)$ in Figure 1f and

2 Figure S3. With the decreasing of R, the calculated system energy of $\mathrm{TMCM}^{+} \cdots\left[\mathrm{SnCl}_{6}\right]^{2-}$

3 decreases as the increased Coulomb attraction, and followed by a quick increase afterwards due to

4 the dominating nuclear repulsion. The halogen bond energy is evaluated from the absolute value

5 of valley energy. The lowest energy of halogen bond is observed to be 0.021 Hartree at a $\mathrm{Cl} \cdots \mathrm{Cl}$

6 bond distance of $3.06 \AA$ for a certain $\mathrm{C}-\mathrm{Cl} \cdots \mathrm{Cl}$ bond angle $\left(\theta=150^{\circ}\right)$. The bond energy increases

7 from 0.021 to 0.024 Hartree (dash line) as $\theta$ increases from $150^{\circ}$ to $180^{\circ}$.

(a)

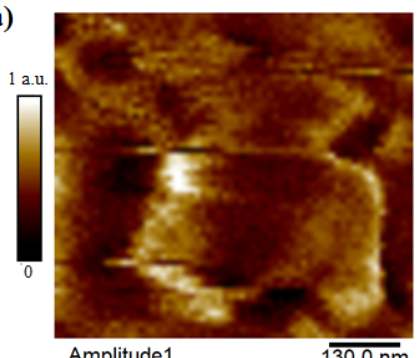

(d)

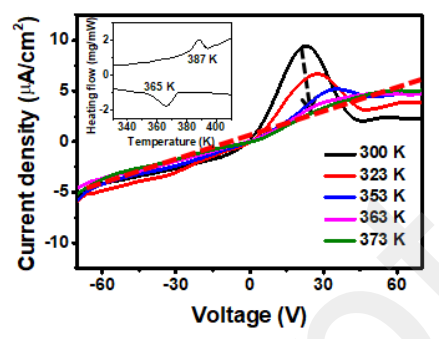

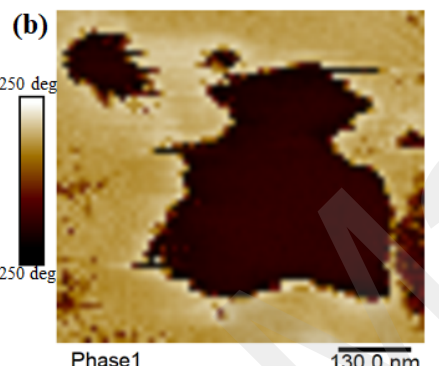

(e)

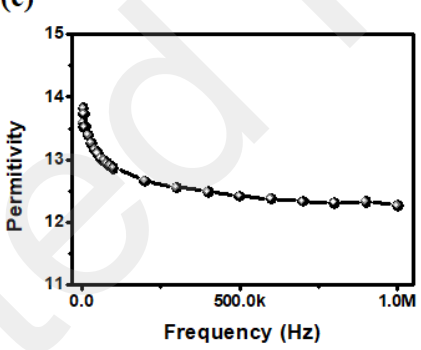

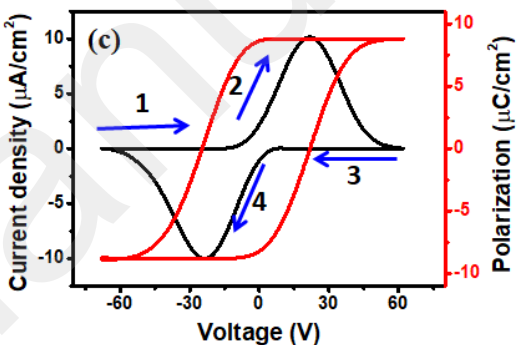

(f)

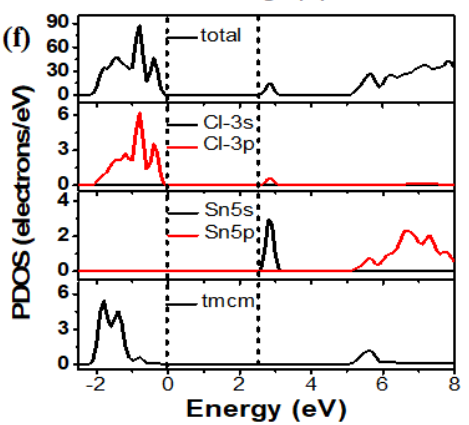

9 Figure 2. Piezoelectric and ferroelectric properties of $\mathbf{T M C M}_{2} \mathrm{SnCl}_{6}$ double perovskite:

10 vertical PFM amplitude (a) and phase (b) images; (c) current density-voltage (J-V) curve and the

11 integrated polarization-voltage (P-V) hysteresis loop of the $\mathrm{TMCM}_{2} \mathrm{SnCl}_{6}$ film at room

12 temperature $\left(25^{\circ} \mathrm{C}\right)$ by using the double-wave method; (d) temperature-dependent $\mathrm{J}-\mathrm{V}$ curves.

13 Voltage was swept from -70 to $70 \mathrm{~V}$. The inset is the differential scanning calorimetry (DSC) curves 
1 of $\mathrm{TMCM}_{2} \mathrm{SnCl}_{6}$ crystals with the scanning rate of $10 \mathrm{~K} / \mathrm{min}$; (c) frequency-dependent permittivity

2 tested from 0.01 to $1 \mathrm{MHz}$; (f) calculated density of states of $\mathrm{TMCM}_{2} \mathrm{SnCl}_{6}$.

3 The $\mathrm{d}_{33}$ of $\mathrm{TMCM}_{2} \mathrm{SnCl}_{6}$ perovskites was measured to be $137 \mathrm{pC} / \mathrm{N}$ by using a quasi-static

4 method in Figure S4. The ferroelectric domains were confirmed by a clear contrast in amplitude

5 and phase images of vertical piezoelectric force microscopy (V-PFM) in Figure 2a-b. There was

6 no crosstalk between the topography (Figure S5b) and the V-PFM phase. Meanwhile, the lateral

7 PFM (L-PFM) was recorded in Figure S5c-d where the signal strength was found relatively weak,

8 indicating that the spontaneous polarization was almost along the out-of-plane direction. ${ }^{33}$ The P-

$9 \quad \mathrm{~V}$ hysteresis loop was measured for $\mathrm{TMCM}_{2} \mathrm{SnCl}_{6}$ films with the thickness of $400 \mu \mathrm{m}$ by using

10 the double-wave method (DWM) in Figure 2c. ${ }^{49,50}$ The arrows in the J-V curve indicate the

11 voltage sweep directions (-60 V $\rightarrow 0 \mathrm{~V} \rightarrow 60 \mathrm{~V} \rightarrow 0 \mathrm{~V} \rightarrow-60 \mathrm{~V}$ ). The J-V curve exhibits two

12 apparent current peaks at the ferroelectric switching voltage of $\pm 23 \mathrm{~V}$. The $\mathrm{E}_{\mathrm{c}}$ of $\mathrm{TMCM}_{2} \mathrm{SnCl}_{6}$,

13 expressed by the ratio of switching voltage to the film thickness, is $0.6 \mathrm{kV} / \mathrm{cm}$. This value is

14 comparable to that of conventional piezo-ceramics such as bulk BTO single crystals $(1 \mathrm{kV} / \mathrm{cm}) .{ }^{51}$

15 The $\mathrm{P}_{\mathrm{s}}$ from the P-V hysteresis loop is up to $8.7 \mu \mathrm{C} / \mathrm{cm}^{2}$, close to the calculated value of $8.4 \pm 0.3$

$16 \mu \mathrm{C} / \mathrm{cm}^{2}$. When the temperature is higher than $T_{\mathcal{c}}$, the ferroelectric material will undergo a phase

17 transition and lose its spontaneous polarization. The phase transition of $\mathrm{TMCM}_{2} \mathrm{SnCl}_{6}$ was

18 considered from orthorhombic to cubic, as indicated by some disappearing diffraction peaks at

19 around $26.3^{\circ}, 33.5^{\circ}$ and $36.5^{\circ}$ in temperature-dependent XRD (Figure S1b). The $\mathrm{T}_{\mathrm{c}}$ of

$20 \mathrm{TMCM}_{2} \mathrm{SnCl}_{6}$ was studied via monitoring the change of peak intensity at $23 \mathrm{~V}$ in the temperature-

21 dependent J-V curves. As indicated in Figure 2d, the current peaks disappear when the

22 temperature rises to $353-363 \mathrm{~K}$. This is consistent to a pair of thermal anomalies at 365/387 $\mathrm{K}$ in

23 the differential scanning calorimetry (DSC) curves (the inset of Figure 2d) and an increase at 350- 
$1380 \mathrm{~K}$ in the temperature dependent permittivity (Figure S1c). The $\mathrm{TMCM}_{2} \mathrm{SnCl}_{6}$ possesses a $\mathrm{T}_{\mathrm{C}}$

2 above room temperature, making it suitable for PNG applications. The $\varepsilon_{\mathrm{r}}$ of perovskite oxide

3 ceramics, such as PZT, is observed as thousands, which stems from the hopping polaron within

4 semiconducting grains and interfacial polarization at the insulating grain boundary. ${ }^{52}$ The

$5 \mathrm{TMCM}_{2} \mathrm{SnCl}_{6}$ exhibits a relative low $\varepsilon_{\mathrm{r}}$ of 14-12 with the frequency from 0.01 to $1 \mathrm{MHz}$ in Figure

6 2e. This should be attributed to the insulating properties of $\mathrm{TMCM}_{2} \mathrm{SnCl}_{6}$ : where the calculated

7 bandgap of above $3.2 \mathrm{eV}$ and a narrow conduction band width are defined by the 5 s orbits of Sn

8 and the 3p orbits of $\mathrm{Cl}$, as indicated in Figure $2 \mathbf{f}$ and Figure S6. According to $\mathrm{g}_{33}=\mathrm{d}_{33} /\left(\varepsilon_{0 \times} \times \varepsilon_{\mathrm{r}}\right)$,

9 where $\varepsilon_{0}$ is the permittivity of free space and $\varepsilon_{\mathrm{r}}=16$, the calculated $\mathrm{g}_{33}$ is $980 \times 10^{-3} \mathrm{~V} \cdot \mathrm{m} / \mathrm{N}$. Notably,

10 a higher $\varepsilon_{\mathrm{r}}$ was chosen to match the following PNG working frequency at $40 \mathrm{~Hz}$. In comparison to

11 traditional metal oxides and other molecular materials listed in Figure 3a (or Table S1), the

$12 \mathrm{TMCM}_{2} \mathrm{SnCl}_{6}$ perovskites are more favorable for the PNG applications due to the both large $\mathrm{d}_{33}$

13 and giant $g_{33}$.
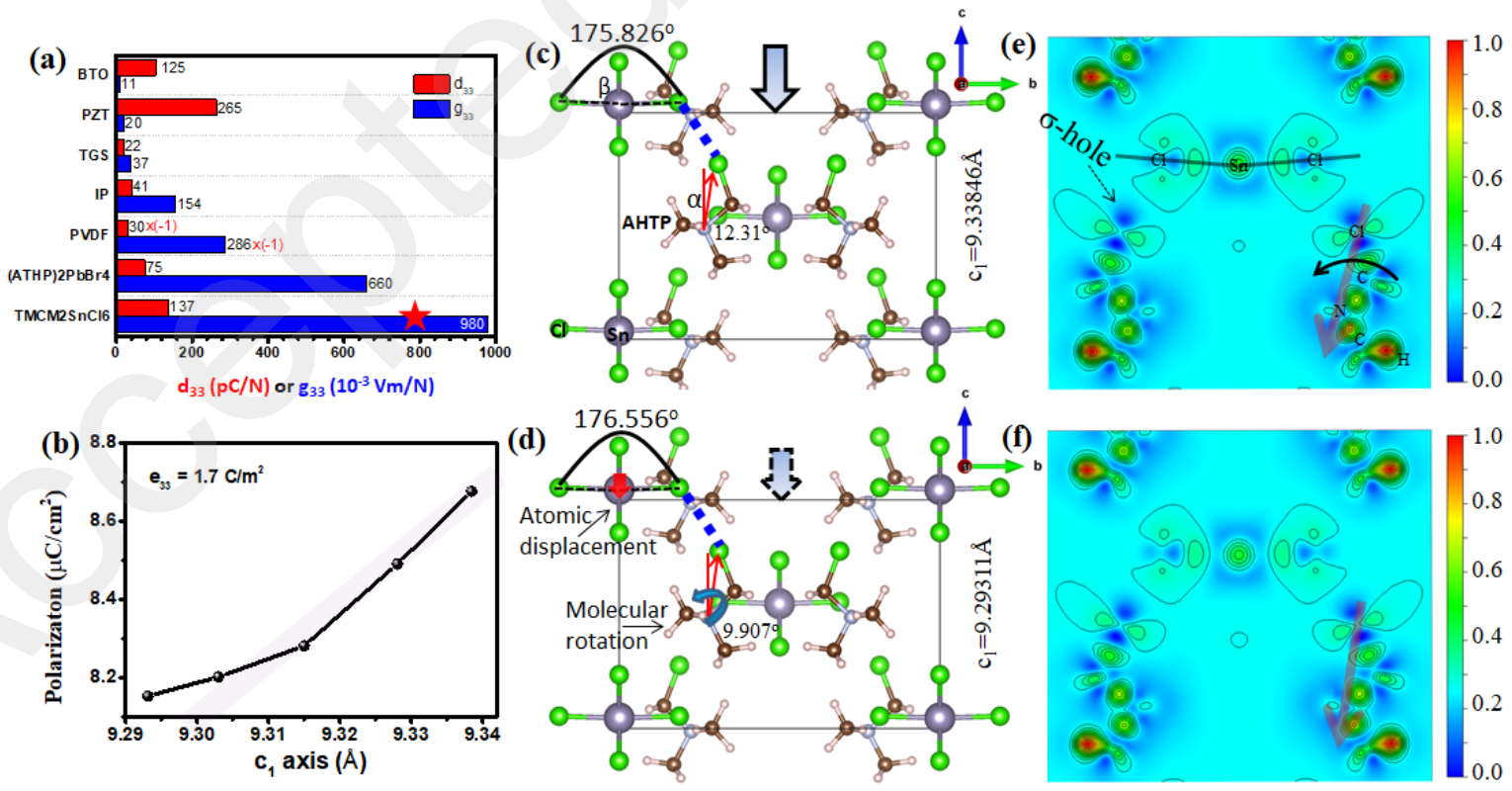
1 of $\mathrm{TMCM}_{2} \mathrm{SnCl}_{6}$ compared with the reported inorganic and molecular materials, including BTO,

2 PZT, Triglycine sulfate (TGS), Imidazolium perchlorate (IP), PVDF, and (ATHP) ${ }_{2} \mathrm{PbBr}_{4}$; (b) the

3 calculated polarization as a function of $\mathrm{c}_{1}$ by using Berry phase method; (c) side views of the

4 unstrained structure and (e) corresponding deformation charge density for c $=9.33864 \AA$; (d) the

5 strained structure and (f) deformation charge density for c $=9.29311 \AA$. The above deformation

6 charge density is in the [001] planes including the $\mathrm{Sn}-\mathrm{Cl} \cdots \mathrm{Cl}-\mathrm{C}$ chain. The blue and red colors

7 represent the electron loss and gain, respectively.

9 To investigate the piezoelectric origin of $\mathrm{TMCM}_{2} \mathrm{SnCl}_{6}$ double perovskites, the polarization

10 ( $\left.\mathrm{P}_{\text {total }}\right)$ was calculated by the Berry phase method as a function of $\mathrm{c}_{1}$, where $\mathrm{c}_{1}$ is the lattice constant

11 during the applied strain along the $\mathrm{c}$ axis (Figure $3 \mathbf{b}$ ). The slope of the linear $\mathrm{P}_{\text {total }}$ vs. $\mathrm{c}_{1}$ curve

12 yields the piezoelectric stress coefficient $\left(\mathrm{e}_{33}\right){ }^{53,54} \mathrm{By}$ fitting the $\mathrm{P}_{\text {total }} \mathrm{vs} . \mathrm{C}_{1} / \mathrm{C}_{0}$ curve in Figure $3 \mathrm{~b}$,

$13 \mathrm{e}_{33}$ is evaluated as $1.7 \mathrm{C} / \mathrm{m}^{2}$. According to the calculated elastic modulus tensor ( $\mathrm{c}_{33}=187.7 \mathrm{kBar}$ )

14 in Table S2, the $d_{33}$ is calculated as $90 \mathrm{pC} / \mathrm{N}$ by using the expression of $\mathrm{d}_{33}=\mathrm{e}_{33} / \mathrm{C}_{33}$. The calculated

$15 \mathrm{~d}_{33}$ is lower than the experimental value of $137 \mathrm{pC} / \mathrm{N}$ as the $\mathrm{P}_{\text {total }}$ contribution resulted from lateral

16 strain was neglected. ${ }^{55}$ Figure $\mathbf{3 c}$ and $\mathbf{3 d}$ show the crystal structure (side view) of unstrained

$17 \mathrm{TMCM}_{2} \mathrm{SnCl}_{6}$ with a lattice constant $\mathrm{c}_{1}$ of $9.33846 \AA$ and that of strained $\mathrm{TMCM}_{2} \mathrm{SnCl}_{6}$ with $\mathrm{c}_{1}$ of

$189.29311 \AA$ (corresponding to a strain of $-0.4 \%$ ), respectively. Under the applied strain, the angle

$19(\alpha)$ in the dipole direction of $\mathrm{TMCM}^{+}$with respect to c axis decreases from $12.31^{\circ}$ to $9.907^{\circ}$.

20 According to the equation of $\mathrm{P}_{\mathrm{TMCM}}=\mu \times \cos (\alpha) / \mathrm{V}_{\mathrm{u}}$, where $\mu$ is the dipole moment of $\mathrm{TMCM}^{+}(4.65$

21 Debye) and $\mathrm{V}_{\mathrm{u}}$ is the cell volume, the polarization from the $\mathrm{TMCM}^{+}$increases when $\alpha$ decreases.

22 The deformation charge density profiles of the unstrained and strained crystal were shown in

23 Figure 3e and 3f, respectively. The $\mathrm{Cl}$ atom in $\mathrm{TMCM}^{+}$is involved in the formation of the covalent 
1 bond. In addition, there is a region of lower electron density ( $\sigma$-hole) where the potential is positive,

2 which generates a cap of depleted electron density on the elongation of the covalent bond. Thus, a

3 halogen-bonding interaction will be formed between the $\mathrm{Cl}$ of $\mathrm{TMCM}^{+}$and the electron-rich $\mathrm{Cl}$

4 atoms in $\left[\mathrm{SnCl}_{6}\right]^{2-}$. Therefore, the rotation of $\mathrm{TMCM}^{+}$can trigger the atomic displacement in

$5\left[\mathrm{SnCl}_{6}\right]^{2-}$ octahedrons simultaneously, indicated by the increased angle $(\beta)$ of $\mathrm{Cl}-\mathrm{Sn}-\mathrm{Cl}$ in

$6\left[\mathrm{SnCl}_{6}\right]^{2-}$ octahedrons from $175.6^{\circ}$ to $176.5^{\circ}$. The polarization from $\left[\mathrm{SnCl}_{6}\right]^{2-}$ is calculated by the

7 equation of $\mathrm{P}_{\mathrm{Sn}}=\mathrm{P}_{\text {total }}-\mathrm{P}_{\text {TMCM }}$. Via fitting the decomposed polarization $\mathrm{P}_{\text {TMCM }}$ and $\mathrm{P}_{\mathrm{Sn}}$ in Figure $\mathrm{S}$,

8 the $\mathrm{e}_{33}$ of $\left[\mathrm{SnCl}_{6}\right]^{2-}$ and $\mathrm{TMCM}^{+}$is $1.5 \mathrm{C} / \mathrm{m}^{2}$ and $0.2 \mathrm{C} / \mathrm{m}^{2}$, respectively. It is clear that the $\left[\mathrm{SnCl}_{6}\right]^{2-}$

9 contributes nearly all of the piezoelectricity. After replacing the asymmetric $\mathrm{TMCM}^{+}$by spherical

10 symmetric $\mathrm{TMA}^{+}$, the $\left[\mathrm{SnCl}_{6}\right]^{2-}$ in $\mathrm{TMA}_{2} \mathrm{SnCl}_{6}$ is not distorted (Figure S8). The polarization from

$11 \mathrm{TMA}_{2} \mathrm{SnCl}_{6}$ is 0 and not changed under an applied strain, indicated the loss of piezoelectricity.

12 Unlike the traditional perovskite ceramics where the piezoelectricity is primarily arising from the

13 atomic displacement (Figure S9), (i) the organic $\mathrm{TMCM}^{+}$in $\mathrm{TMCM}_{2} \mathrm{SnCl}_{6}$ can break its crystal

14 symmetry and (ii) the piezoelectricity in $\mathrm{TMCM}_{2} \mathrm{SnCl}_{6}$ is from the halogen bond-mediated

15 synergistic movement of atomic displacement in inorganic $\left[\mathrm{SnCl}_{6}\right]^{2-}$ octahedrons and the

16 molecular rotation of $\mathrm{TMCM}^{+}$.

17 The piezoelectricity in the $\mathrm{TMCM}_{2} \mathrm{SnCl}_{6}$ was further demonstrated by the outputs of fabricated

18 PNGs. The precursor of piezoelectric composite films was prepared via dispersing 10 wt. \%

$19 \mathrm{TMCM}_{2} \mathrm{SnCl}_{6}$ nanoparticles (NPs) uniformly in the PDMS by mechanical stirring (Figure S10).

20 The size of the NPs was in the range of 200-1000 nm, as shown in the SEM and elemental mapping

21 (Figure S11b-c). The films were grown via drop-casting the above precursor solution on a glass

22 substrate (Figure S11a). After the drop-casting, NPs with a larger size tended to precipitate to the

23 bottom of central area rather than diffuse to the marginal area (Figure S11a, d-f). The fraction of 
$1 \mathrm{TMCM}_{2} \mathrm{SnCl}_{6} \mathrm{NPs}$ in the composite film for the PNG integration was $18 \mathrm{wt}$ \% measured in the

2 dotted circle in Figure S11d by the SEM-EDS. The film thickness at the central area was $300 \mu \mathrm{m}$.

3 Finally, the $\mathrm{TMCM}_{2} \mathrm{SnCl}_{6} @ \mathrm{PDMS}$ composite film was sandwiched between two copper 4 electrodes for PNG fabrication (Figure 4a and Figure S12) (see the experimental details in the 5 supporting information).

(a)

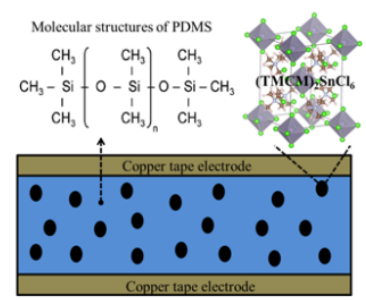

(d)

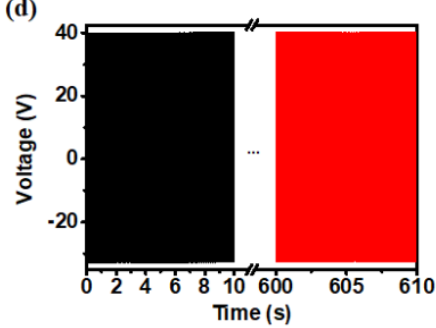

(g)

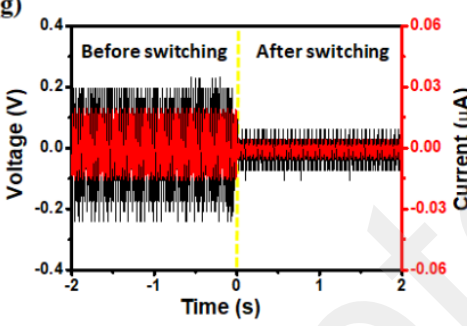

(b)

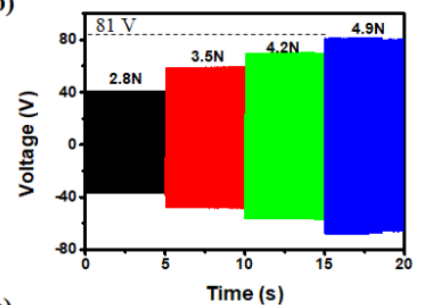

(e)

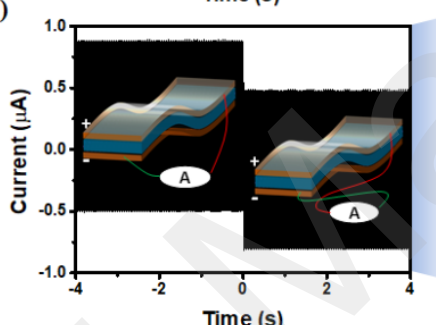

(h)

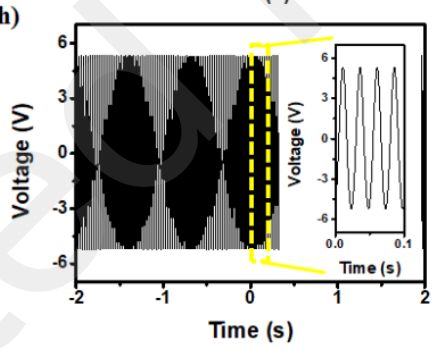

(c)

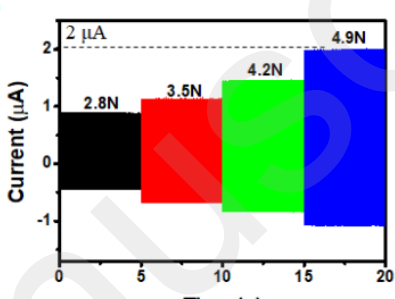

(f)

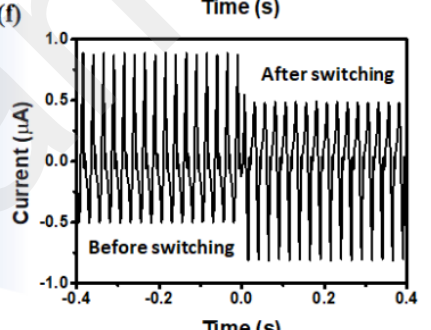

(i)

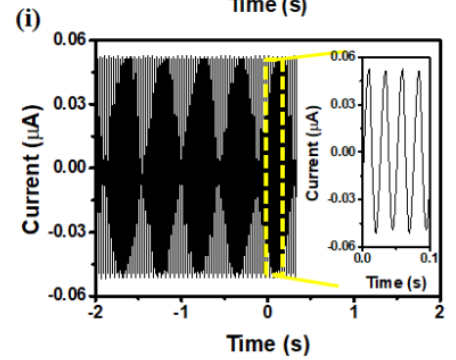

7 Figure 4. The piezoelectric output of single PNG: (a) device structure of PNGs via inserting TMCM $2 \mathrm{SnCl}_{6} @ \mathrm{PDMS}$ composite film between copper electrodes; (b) $\mathrm{V}_{\mathrm{oc}}$ and (c) I $\mathrm{I}_{\mathrm{sc}}$ of PNGs with

9 the force from 2.8 to $4.9 \mathrm{~N}(40 \mathrm{~Hz})$; (d) the device reliability tested for 10 mins; (e) $\mathrm{I}_{\mathrm{sc}}$ and (f)

10 enlarged view of the PNGs under forward and reverse electrical connections. The inset is schematic

11 diagrams of the PNGs under forward and reverse connections; (g) polarity switching test of $\mathrm{V}_{\text {oc }}$

12 (black curve) and $\mathrm{I}_{\mathrm{sc}}$ (red curve) of pure PDMS based devices; (h) $\mathrm{V}_{\mathrm{oc}}$ and (k) $\mathrm{I}_{\mathrm{sc}}$ of PNGs based

13 on $\mathrm{TMCM}_{2} \mathrm{SnCl}_{6} @ \mathrm{PDMS}$ film (without poling). For the Figures 4d-i, the applied mechanical 
excitation is $(2.8 \mathrm{~N}, 40 \mathrm{~Hz})$.

2 The outputs of the TMCM${ }_{2} \mathrm{SnCl}_{6} @ P D M S$ based PNGs was measured by mounting the device

3 on a shaker in a vertical compressing and releasing process (Figure S13). For the PNGs with 18

4 wt. \% $\mathrm{TMCM}_{2} \mathrm{SnCl}_{6}$ in the composite film, the output $\mathrm{V}_{\mathrm{oc}}$ and $\mathrm{I}_{\mathrm{sc}}$ of $40 \mathrm{~V}$ and $0.9 \mu \mathrm{A}$ was achieved

5 under the force of $2.8 \mathrm{~N}$ at a frequency of $40 \mathrm{~Hz}$. The device output is reproducible as indicated

6 by the statistical analysis of $\mathrm{V}_{\text {ос }}$ in Figure S14. With the applied force increased from 2.8 to 4.9

$7 \mathrm{~N}$, the piezoelectric outputs $\left(\mathrm{V}_{\text {oc }}\right.$ and $\left.\mathrm{I}_{\mathrm{sc}}\right)$ of the PNGs increase linearly in Figure 4b-c. The $\mathrm{V}_{\text {oc }}$

8 and $\mathrm{I}_{\mathrm{sc}}$ reach $81 \mathrm{~V}$ and $2 \mu \mathrm{A}$, respectively, at an applied force of $4.9 \mathrm{~N}$. The frequency-dependent

$9 \quad \mathrm{~V}_{\mathrm{oc}}$ and $\mathrm{I}_{\mathrm{sc}}$ are shown in Figure S15 as the force keeps 2.8N. Meanwhile, the device outputs were

10 also recorded at low frequency (3 Hz) via a cylindrical hammer mounted on a linear motor and a

11 metallic stopper. The $\mathrm{V}_{\text {oc }}$ and current density $\left(\mathrm{J}_{\mathrm{sc}}\right)$ were measured as $11.6 \mathrm{~V}$ and $1.17 \mu \mathrm{A} / \mathrm{cm}^{2}$,

12 respectively, at an applied pressure of $0.032 \mathrm{MPa}$ (Figure S16). The concentration of

$13 \mathrm{TMCM}_{2} \mathrm{SnCl}_{6}$ on the electricity generation capacity of the PNGs was optimized in Figure S18.

14 The output voltage and current gradually increase to $72 \mathrm{~V}$ and $1.3 \mu \mathrm{A}$ with the increasing mass

15 fraction of $\mathrm{TMCM}_{2} \mathrm{SnCl}_{6}$ NPs up to 29 wt. \%, under an applied force of $2.8 \mathrm{~N}$. In comparison with

16 traditional inorganic perovskite ceramics in Table S3, the $\mathrm{TMCM}_{2} \mathrm{SnCl}_{6}$ were prepared at room

17 temperature and the PNGs exhibit the competitive piezoelectric outputs. The reliability of the

18 PNGs was explored by continually testing the device for 10 minutes and the amplitude of the

19 output voltage shows a negligible degradation (Figure 4d and Video S1), confirming its excellent

20 mechanical durability. Finally, the PNGs were used as an integrated power source to meet up the

21 energy demand of practical electrical loads via harvesting energy from local environment, such as

22 SWCN (see the details in Figure S17 and Video S2). 
To demonstrate the generated outputs were originating from the piezoelectric phenomenon, the

2 following experiments were conducted: (i) the measured current output of the PNGs switched its

3 polarity during the electrical connection reversal (Figure 4e-f and Video S3), indicating that the

4 outputs were produced from the PNGs; (ii) For comparison, the output $\mathrm{V}_{\text {oc }}$ and $\mathrm{I}_{\mathrm{sc}}$ of PNGs made

5 from pure PDMS were merely $0.2 \mathrm{~V}$ and $0.02 \mu \mathrm{A}$ and lacking of the polarity switching property in

6 Figure 4g. The $\mathrm{V}_{\text {oc }}$ is enhanced with the loading $\mathrm{TMCM}_{2} \mathrm{SnCl}_{6} \mathrm{NPs}$ in the composite film as shown

7 in Figure S18. These verify the claim that - the high performance of PNGs is determined by the

8 incorporation of $\mathrm{TMCM}_{2} \mathrm{SnCl}_{6}$; (iii) the effect of electrical poling on the PNG outputs was

9 investigated (see the poling procedures in the experimental section). Compared with the outputs

10 of unpoling PNGs (Figure 4h-k), the PNGs after poling at $4.5 \mathrm{kV}$ (Figure 4b-c) exhibited drastic

11 increase in $\mathrm{V}_{\text {oc }}$ (from 5.4 to $40 \mathrm{~V}$ ) and $\mathrm{I}_{\mathrm{sc}}$ (from 0.05 to $0.9 \mu \mathrm{A}$ ) under the same measurement

12 conditions (2.8 N, $40 \mathrm{~Hz})$. A detailed comparison of output voltage of PNGs measured under

13 various applied poling fields is shown in Figure S19.

14 In summary, a novel vacancy-ordered double perovskite of $\mathrm{TMCM}_{2} \mathrm{SnCl}_{6}$ with a large $\mathrm{d}_{33}$ of

$15137 \mathrm{pC} / \mathrm{N}$ and giant $\mathrm{g}_{33}$ of $980 \times 10^{-3} \mathrm{~V} \cdot \mathrm{m} / \mathrm{N}$ was proposed for the energy harvesting applications.

16 The $\mathrm{TMCM}_{2} \mathrm{SnCl}_{6}$ perovskite possesses a high $\mathrm{P}_{\mathrm{s}}$ of $8.7 \mu \mathrm{C} / \mathrm{cm}^{2}$, a high $\mathrm{T}_{\mathrm{c}}$ of $365 \mathrm{~K}$, and a low $\mathrm{E}_{\mathrm{c}}$

17 of $0.6 \mathrm{kV} / \mathrm{cm}$. The ultrahigh piezoelectricity in $\mathrm{TMCM}_{2} \mathrm{SnCl}_{6}$ is attributed to the halogen bonding-

18 mediated synergistic movements of atomic displacement in the inorganic $\left[\mathrm{SnCl}_{6}\right]^{2-}$ octahedron and

19 the dipole alignment of organic $\mathrm{TMCM}^{+}$. The piezoelectric coefficients from the $\mathrm{TMCM}_{2} \mathrm{SnCl}_{6}$

20 was firstly experimentally measured, then verified by DFT study, and finally confirmed by the

21 piezoelectric output of the PNGs. The piezoelectric composite films were prepared by dispersing

$22 \mathrm{TMCM}_{2} \mathrm{SnCl}_{6}$ NPs into the PDMS matrix. The peak values of $\mathrm{V}_{\text {oc }}$ and $\mathrm{I}_{\mathrm{sc}}$ of the fabricated PNGs

23 reached up to $81 \mathrm{~V}$ and $2 \mu \mathrm{A}$ at an applied mechanical excitation of (4.9 N, $40 \mathrm{~Hz}$ ). The SWCN 
1 was successfully driven by the PNG. This work not only opens up a door for designing novel

2 piezoelectric OIHPs with ultrahigh $\mathrm{d}_{33}$ and $\mathrm{g}_{33}$, but also paves the way for its real applications in 3 self-powered electronics.

\section{Supporting Information}

5 The Supporting Information is available free of charge at https://pubs.acs.org/doi/...

6 Experimental methods, computational details, XRD, XPS, $\mathrm{d}_{33}$, and calculated band structure of

$7 \mathrm{TMCM}_{2} \mathrm{SnCl}_{6}$ crystals, digital photograph, SEM images and piezoelectric potential simulation of

$8 \mathrm{TMCM}_{2} \mathrm{SnCl}_{6} @ \mathrm{PDMS}$ composite films, digital photos, frequency-dependent outputs of single

9 PNG, real application of PNG for SWCN, output performance comparison of PNGs based on

10 PDMS matrix, table for calculated elastic modulus, and Videos (MP4) for device stability, output

11 switching, and SWCN.

12 Notes

13 The authors declare no competing financial interest.

\section{Acknowledgements}

15 This work is supported by Natural Science and Engineering Research Council of Canada,

16 Ontario Centers of Excellence, and University of Waterloo. The authors thank to Prof. Ning Yan

17 and Dr. Nicolas Tanguy from University of Toronto for their help with the DSC measurement.

\section{References}

21 (1) Pan, C.; Zhai, J.; Wang, Z. L., Piezotronics and Piezo-phototronics of Third Generation

22 Semiconductor Nanowires. Chem. Rev. 2019, 119 (15), 9303-9359. 
1 (2) Kim, I.; Roh, H.; Yu, J.; Jayababu, N.; Kim, D., Boron Nitride Nanotube-Based Contact

2 Electrification-Assisted Piezoelectric Nanogenerator as a Kinematic Sensor for Detecting the 3 Flexion-Extension Motion of a Robot Finger. ACS Energy Lett. 2020, 5 (5), 1577-1585.

4 (3) Niu, X.; Jia, W.; Qian, S.; Zhu, J.; Zhang, J.; Hou, X.; Mu, J.; Geng, W.; Cho, J.; He, J.;

5 Chou, X., High-Performance PZT-Based Stretchable Piezoelectric Nanogenerator. ACS

$6 \quad$ Sustainable Chem. Eng. 2018, 7 (1), 979-985.

7 (4) Biswas, P.; Hoque, N. A.; Thakur, P.; Saikh, M. M.; Roy, S.; Khatun, F.; Bagchi, B.; Das, S., 8 Highly Efficient and Durable Piezoelectric Nanogenerator and Photo-power cell Based on 9 CTAB Modified Montmorillonite Incorporated PVDF Film. ACS Sustainable Chem. Eng. $10 \quad$ 2019, 7 (5), 4801-4813.

11 (5) Pandey, R.; Sb, G.; Grover, S.; Singh, S. K.; Kadam, A.; Ogale, S.; Waghmare, U. V.; Rao,

12 V. R.; Kabra, D., Microscopic Origin of Piezoelectricity in Lead-Free Halide Perovskite:

13 Application in Nanogenerator Design. ACS Energy Lett. 2019, 4 (5), 1004-1011.

14 (6) Deutz, D. B.; Mascarenhas, N. T.; Schelen, J. B. J.; de Leeuw, D. M.; van der Zwaag, S.;

15 Groen, P., Flexible Piezoelectric Touch Sensor by Alignment of Lead-Free Alkaline Niobate

16 Microcubes in PDMS. Adv. Funct. Mater. 2017, 27 (24), 1700728.

17 (7) Gao, X.; Zheng, M.; Yan, X.; Fu, J.; Hou, Y.; Zhu, M., High Performance Piezocomposite

18 for Flexible Device Application. Nanoscale 2020, 12, 5175-5185

19 (8) Hinchet, R.; Khan, U.; Falconi, C.; Kim, S., Piezoelectric Properties in Two-Dimensional

20 Materials: Simulations and Experiments. Materials Today 2018, 21 (6), 611-630.

21 (9) Li, W.; Wu, N.; Zhong, J.; Zhong, Q.; Zhao, S.; Wang, B.; Cheng, X.; Li, S.; Liu, K.; Hu, B.;

22 Zhou, J., Theoretical Study of Cellular Piezoelectret Generators. Adv. Funct. Mater. 2016, 26

23 (12), 1964-1974. 
1 (10) Dutta, B.; Kar, E.; Bose, N.; Mukherjee, S., NiO@SiO2/PVDF: A Flexible Polymer

2 Nanocomposite for a High Performance Human Body Motion-Based Energy Harvester and

3 Tactile e-Skin Mechanosensor. ACS Sustainable Chem. Eng. 2018, 6 (8), 10505-10516.

4 (11) Lee, J.-H.; Yoon, H.-J.; Kim, T. Y.; Gupta, M. K.; Lee, J. H.; Seung, W.; Ryu, H.; Kim, S.-

5 W., Micropatterned P(VDF-TrFE) Film-Based Piezoelectric Nanogenerators for Highly

6 Sensitive Self-Powered Pressure Sensors. Adv. Funct. Mater. 2015, 25 (21), 3203-3209.

7 (12) Mao, Y.; Zhao, P.; McConohy, G.; Yang, H.; Tong, Y.; Wang, X., Sponge-Like

8 Piezoelectric Polymer Films for Scalable and Integratable Nanogenerators and Self-

$9 \quad$ Powered Electronic Systems. Adv. Energy Mater. 2014, 4 (7), 1301624.

10 (13) Pi, Z.; Zhang, J.; Wen, C.; Zhang, Z.-b.; Wu, D., Flexible Piezoelectric Nanogenerator

11 Made of Poly(vinylidenefluoride-co-trifluoroethylene) (PVDF-TrFE) Thin Film. Nano

12 Energy 2014, 7, 33-41.

13 (14) Meng, X.; Wen, X.; Qin, G., DFT Study on Elastic and Piezoelectric Properties of

14 Tetragonal $\mathrm{BaTiO}_{3}$. Comput. Mater. Sci. 2010, 49 (4), S372-S377.

15 (15) Jeong, C. K.; Kim, I.; Park, K. I.; Oh, M. H.; Paik, H.; Hwang, G. T.; No, K.; Nam, Y. S.;

16 Lee, K. J., Virus-Directed Design of a Flexible $\mathrm{BaTiO}_{3}$ Nanogenerator. ACS Nano 2013, 7

$17 \quad$ (12), 11016-25.

18 (16) Zhang, G.; Liao, Q.; Zhang, Z.; Liang, Q.; Zhao, Y.; Zheng, X.; Zhang, Y., Novel

19 Piezoelectric Paper-Based Flexible Nanogenerators Composed of $\mathrm{BaTiO}_{3}$ Nanoparticles and

20 Bacterial Cellulose. Adv. Sci. 2016, 3 (2), 1500257.

21 (17) Wu, W.; Bai, S.; Yuan, M.; Qin, Y.; Wang, Z. L.; Jing, T., Lead Zirconate Titanate

22 Nanowire Textile Nanogenerator for Wearable Energy-Harvesting and Self-Powered

23 Devices. ACS Nano 2012, 6 (7), 6231-5. 
1 (18) Bowen, C. R.; Kim, H. A.; Weaver, P. M.; Dunn, S., Piezoelectric and Ferroelectric Materials and Structures for Energy Harvesting Applications. Energy Environ. Sci. 2014, 7 (1), 25-44.

(19) Yan, Y.; Zhou, J. E.; Maurya, D.; Wang, Y. U.; Priya, S., Giant Piezoelectric Voltage Coefficient in Grain-Oriented Modified $\mathrm{PbTiO}_{3}$ Material. Nat. Commun. 2016, 7, 13089.

(20) Li, W.; Wang, Z.; Deschler, F.; Gao, S.; Friend, R. H.; Cheetham, A. K., Chemically Diverse and Multifunctional Hybrid Organic-Inorganic Perovskites. Nat. Rev. Mater 2017, $2(3), 16099$.

(21) Zhao, X. G.; Yang, J. H.; Fu, Y.; Yang, D.; Xu, Q.; Yu, L.; Wei, S. H.; Zhang, L., Design of Lead-Free Inorganic Halide Perovskites for Solar Cells via Cation-Transmutation. J. Am. Chem. Soc. 2017, 139 (7), 2630-2638.

(22) Xiao, Z.; Meng, W.; Wang, J.; Mitzi, D. B.; Yan, Y., Searching for Promising New Perovskite-Based Photovoltaic Absorbers: the Importance of Electronic Dimensionality. Mater. Horiz. 2017, 4 (2), 206-216.

(23) Huang, G.; Wang, C.; Xu, S.; Zong, S.; Lu, J.; Wang, Z.; Lu, C.; Cui, Y., Postsynthetic Doping of $\mathrm{MnCl}_{2}$ Molecules into Preformed $\mathrm{CsPbBr}_{3}$ Perovskite Nanocrystals via a Halide Exchange-Driven Cation Exchange. Adv. Mater. 2017, 29 (29), 1700095.

(24) Manser, J. S.; Saidaminov, M. I.; Christians, J. A.; Bakr, O. M.; Kamat, P. V., Making and Breaking of Lead Halide Perovskites. Acc. Chem. Res. 2016, 49 (2), 330-8.

(25) Bernasconi, A.; Malavasi, L., Direct Evidence of Permanent Octahedra Distortion in MAPbBr3 Hybrid Perovskite. ACS Energy Lett. 2017, 2 (4), 863-868.

(26) Kim, Y.-J.; Dang, T.-V.; Choi, H.-J.; Park, B.-J.; Eom, J.-H.; Song, H.-A.; Seol, D.; Kim, Y.; Shin, S.-H.; Nah, J.; Yoon, S.-G., Piezoelectric Properties of $\mathrm{CH}_{3} \mathrm{NH}_{3} \mathrm{PbI}_{3}$ Perovskite 
Thin Films and Their Applications in Piezoelectric Generators. J. Mater.Chem. A 2016, 4 (3), 756-763.

(27) Jella, V.; Ippili, S.; Eom, J.-H.; Pammi, S. V. N.; Jung, J.-S.; Tran, V.-D.; Nguyen, V. H.; Kirakosyan, A.; Yun, S.; Kim, D.; Sihn, M. R.; Choi, J.; Kim, Y.-J.; Kim, H.-J.; Yoon, S.G., A Comprehensive Review of Flexible Piezoelectric Generators Based on OrganicInorganic Metal Halide Perovskites. Nano Energy 2019, 57, 74-93.

(28) Shahrokhi, S.; Gao, W.; Wang, Y.; Anandan, P. R.; Rahaman, M. Z.; Singh, S.; Wang, D.; Cazorla, C.; Yuan, G.; Liu, J. M.; Wu, T., Emergence of Ferroelectricity in Halide Perovskites. Small Methods 2020, 4 (8), 2000149.

(29) Khan, A. A.; Rana, M. M.; Huang, G.; Mei, N.; Saritas, R.; Wen, B.; Zhang, S.; Voss, P.; Rahman, E.-A.; Leonenko, Z.; Islam, S.; Ban, D., Maximizing Piezoelectricity by SelfAssembled Highly Porous Perovskite-Polymer Composite Films to Enable the Internet of Things. J. Mater. Chem. A 2020, 8 (27), 13619-13629.

(30) Ippili, S.; Jella, V.; Kim, J.; Hong, S.; Yoon, S. G., Unveiling Predominant Air-Stable Organotin Bromide Perovskite toward Mechanical Energy Harvesting. ACS Appl. Mater. Interfaces 2020, 12 (14), 16469-16480.

(31) Jella, V.; Ippili, S.; Yoon, S.-G., Halide (Cl/Br)-Incorporated Organic-Inorganic Metal Trihalide Perovskite Films: Study and Investigation of Dielectric Properties and Mechanical Energy Harvesting Performance. ACS Appl. Electron. Mater. 2020, 2 (8), 2579-2590.

(32) Liao, W. Q.; Zhao, D.; Tang, Y. Y.; Zhang, Y.; Li, P. F.; Shi, P. P.; Chen, X. G.; You, Y. M.; Xiong, R. G., A Molecular Perovskite Solid Solution with Piezoelectricity Stronger Than Lead Zirconate Titanate. Science 2019, 363 (6432), 1206-1210. 
1 (33) You, Y. M.; Liao, W. Q.; Zhao, D.; Ye, H. Y.; Zhang, Y.; Zhou, Q.; Niu, X.; Wang, J.; Li,

$2 \quad$ P. F.; Fu, D. W.; Wang, Z.; Gao, S.; Yang, K.; Liu, J. M.; Li, J.; Yan, Y.; Xiong, R. G., An

3 Organic-Inorganic Perovskite Ferroelectric with Large Piezoelectric Response. Science

$4 \quad$ 2017, 357 (6348), 306-309.

5 (34) Chen, X. G.; Song, X. J.; Zhang, Z. X.; Li, P. F.; Ge, J. Z.; Tang, Y. Y.; Gao, J. X.; Zhang,

6 W. Y.; Fu, D. W.; You, Y. M.; Xiong, R. G., Two-Dimensional Layered Perovskite

7 Ferroelectric with Giant Piezoelectric Voltage Coefficient. J. Am. Chem. Soc. 2020, 142 (2),

$8 \quad 1077-1082$.

9 (35) Deswal, S.; Singh, S. K.; Pandey, R.; Nasa, P.; Kabra, D.; Praveenkumar, B.; Ogale, S.;

10 Boomishankar, R., Neutral 1D Perovskite-Type ABX 3 Ferroelectrics with High Mechanical

11 Energy Harvesting Performance. Chem. Mater. 2020, 32 (19), 8333-8341.

12 (36) Zhang, Z. X.; Zhang, H. Y.; Zhang, W.; Chen, X. G.; Wang, H.; Xiong, R. G.,

13 Organometallic-Based Hybrid Perovskite Piezoelectrics with a Narrow Band Gap. J. Am.

14 Chem. Soc. 2020, 142 (41), 17787-17794.

15 (37) Zhang, Y.; Song, X.-J.; Zhang, Z.-X.; Fu, D.-W.; Xiong, R.-G., Piezoelectric Energy

16 Harvesting Based on Multiaxial Ferroelectrics by Precise Molecular Design. Matter 2020, 2

$17 \quad$ (2), $1-14$.

18 (38) Vijayakanth, T.; Ram, F.; Praveenkumar, B.; Shanmuganathan, K.; Boomishankar, R.,

19 Piezoelectric Energy Harvesting from a Ferroelectric Hybrid Salt $\left[\mathrm{Ph}_{3} \mathrm{MeP}_{4}\left[\mathrm{Ni}(\mathrm{NCS})_{6}\right]\right.$

20 Embedded in a Polymer Matrix. Angew. Chem. Int. Ed. 2020, 59 (26), 10368-10373. 
(39) Morss, L. R.; Carnall, W. T.; Williams, C. W.; Fahey, J. A.; Fuger, J.; Meyer, G.; Irmler, M., Syntheses and X-ray Diffraction Studies of $\left[\mathrm{N}\left(\mathrm{CH}_{3}\right)_{4}\right]_{2} \mathrm{BkCl}_{6}$ and $\left[\mathrm{N}\left(\mathrm{CH}_{3}\right)_{4}\right]_{2} \mathrm{ZrCl}_{6}$; Absorption Spectrum of $\mathrm{Bk}^{4+}$ in $\left[\mathrm{N}\left(\mathrm{CH}_{3}\right)_{4}\right]_{2} \mathrm{BkCl}_{6}$. J. Less-Common Met. 1991, 169 (1), 1-8.

(40) Karim, M. M. S.; Ganose, A. M.; Pieters, L.; Winnie Leung, W. W.; Wade, J.; Zhang, L.; Scanlon, D. O.; Palgrave, R. G., Anion Distribution, Structural Distortion, and SymmetryDriven Optical Band Gap Bowing in Mixed Halide $\mathrm{Cs}_{2} \mathrm{SnX}_{6}$ Vacancy Ordered Double Perovskites. Chem. Mater. 2019, 31 (22), 9430-9444.

(41) Maughan, A. E.; Ganose, A. M.; Almaker, M. A.; Scanlon, D. O.; Neilson, J. R., Tolerance Factor and Cooperative Tilting Effects in Vacancy-Ordered Double Perovskite Halides. Chem. Mater. 2018, 30 (11), 3909-3919.

(42) Fedorovskiy, A. E.; Drigo, N. A.; Nazeeruddin, M. K., The Role of Goldschmidt's Tolerance Factor in the Formation of $\mathrm{A}_{2} \mathrm{BX}_{6}$ Double Halide Perovskites and its Optimal Range. Small Methods 2019, 0 (0), 1900426.

(43) Autillo, M.; Wilson, R. E., Phase Transitions in Tetramethylammonium Hexachlorometalate Compounds (TMA) ${ }_{2} \mathrm{MCl}_{6}(\mathrm{M}=\mathrm{U}, \mathrm{Np}, \mathrm{Pt}, \mathrm{Sn}, \mathrm{Hf}, \mathrm{Zr})$. Eur. J. Inorg. Chem. 2017, 2017 (41), 4834-4839.

(44) Tan, Z.; Li, J.; Zhang, C.; Li, Z.; Hu, Q.; Xiao, Z.; Kamiya, T.; Hosono, H.; Niu, G.; Lifshitz, E.; Cheng, Y.; Tang, J., Highly Efficient Blue-Emitting Bi-Doped $\mathrm{Cs}_{2} \mathrm{SnCl}_{6}$ Perovskite Variant: Photoluminescence Induced by Impurity Doping. Adv. Funct. Mater. 2018, 28 (29), 1801131.

(45)Hua, X. N.; Liao, W. Q.; Tang, Y. Y.; Li, P. F.; Shi, P. P.; Zhao, D.; Xiong, R. G., A RoomTemperature Hybrid Lead Iodide Perovskite Ferroelectric. J. Am. Chem. Soc. 2018, 140 (38), 12296-12302. 
1 (46) Liao, W. Q.; Tang, Y. Y.; Li, P. F.; You, Y. M.; Xiong, R. G., Competitive Halogen Bond

2 in the Molecular Ferroelectric with Large Piezoelectric Response. J. Am. Chem. Soc. 2018, 3140 (11), 3975-3980.

4 (47) Cavallo, G.; Metrangolo, P.; Milani, R.; Pilati, T.; Priimagi, A.; Resnati, G.; Terraneo, G., 5 The Halogen Bond. Chem. Rev. 2016, 116 (4), 2478-601.

6 (48) Huang, G.; Wang, C.; Zhang, H.; Xu, S.; Xu, Q.; Cui, Y., Post-Healing of Defects: an $7 \quad$ Alternative Way for Passivation of Carbon-Based Mesoscopic Perovskite Solar Cells via $8 \quad$ Hydrophobic Ligand Coordination. J. Mater. Chem. A 2018, 6 (6), 2449-2455.

9 (49) Fukunaga, M.; Noda, Y., New Technique for Measuring Ferroelectric and Antiferroelectric

11 (50) Hu, L.; Dalgleish, S.; Matsushita, M. M.; Yoshikawa, H.; Awaga, K., Storage of an Electric 12 Field for Photocurrent Generation in Ferroelectric-Functionalized Organic Devices. Nat. 13 Commun. 2014, 5, 3279.

14 (51) Trithaveesak, O.; Schubert, J.; Buchal, C., Ferroelectric Properties of Epitaxial $\mathrm{BaTiO}_{3} \mathrm{Thin}$ Films and Heterostructures on Different Substrates. J. Appl. Phys. 2005, 98 (11), 114101.

(52) Han, H.; Voisin, C.; Guillemet-Fritsch, S.; Dufour, P.; Tenailleau, C.; Turner, C.; Nino, J. C., Origin of Colossal Permittivity in $\mathrm{BaTiO}_{3}$ via Broadband Dielectric Spectroscopy. J. Appl. Phys. 2013, 113 (2), 024102.

(53) Liu, S.; Zheng, F.; Grinberg, I.; Rappe, A. M., Photoferroelectric and Photopiezoelectric Properties of Organometal Halide Perovskites. J. Phys. Chem. Lett. 2016, 7 (8), 1460-5.

(54) Shi, J.; Grinberg, I.; Wang, X.; Rappe, A. M., Atomic Sublattice Decomposition of Piezoelectric Response in Tetragonal $\mathrm{PbTiO}_{3}, \mathrm{BaTiO}_{3}$, andKNbO . Phys. Rev. B 2014, 89 (9), 094105. 
1 (55) Tholander, C.; Abrikosov, I. A.; Hultman, L.; Tasnádi, F., Volume Matching Condition to Establish the Enhanced Piezoelectricity in Ternary (Sc, Y) ${ }_{0.5}(\mathrm{Al}, \mathrm{Ga}, \mathrm{In})_{0.5} \mathrm{~N}$ Alloys. Phys.

$3 \quad$ Rev. B 2013, 87 (9), 094107. 